\title{
EFFECT OF THE CUTTING TOOL GEOMETRY ON THE TOOL WEAR RESISTANCE WHEN MACHINING INCONEL 625
}

\author{
Tomáš Zlámal', Jiří Hajnyš , Jana Petrů', Ivan Mrkvica' \\ 1 VSB-Technical University of Ostrava, Faculty of Mechanical Engineering, 17. listopadu 2172/15 1, 708 00, Ostrava, \\ Czech Republic, e-mail: tomas.zlamal@vsb.cz, jiri.hajnys@vsb.cz, jana.petru@vsb.cz, ivan.mrkvica@vsb.cz
}

Received: 2018.01 .15 Accepted: 2018.02.01 Published: 2018.03.01

\begin{abstract}
The paper deals with the design of a suitable cutting geometry of a tool for the machining of the Inconel 625 nickel alloy. This alloy is among the hard-to-machine refractory alloys that cause very rapid wear on cutting tools. Therefore, SNMG and RCMT indexable cutting insert were used to machine the alloy. The selected insert geometry should prevent notch wear and extend tool life. The alloy was machined under predetermined cutting conditions. The angle of the main edge and thus the size and nature of the wear changed with the depth of the material layer being cut. The criterion for determining a more suitable cutting geometry was the tool's durability and the roughness of the machined surface.
\end{abstract}

Keywords: wear resistance, Inconel 625 , cutting tool geometry, entering angle

\section{INTRODUCTION}

With the increasing demands on the working of special refractory and heat-resistant alloys, there are growing demands on technology, cutting tools, cutting conditions and the environment. Inconel 625 alloy is a nickel alloy, which shows a number of undesirable effects when subjected to chip machining. Low thermal conductivity, mechanical hardening, high toughness and hard carbides in the material structure are the cause of the negative environment affecting the cutting tool edge. Intensive mechanical and thermal strain affecting the cutting edge of the tool causes rapid and uncontrollable wear leading to reduced durability of the cutting tool and reduced efficiency of the machining process.

One of the most common forms of tool wear in nickel alloy machining is notching. When the tool is in contact with the hardened surface layer of the machined material, the rake and especially the flank of the cutting tool become subject to notch wear occurring at a distance equivalent to the maximum cutting depth. This form of wear is more likely to occur with tools that have been in contact with the machined material for a longer period of time, and are therefore exposed to high temperature at the cutting point. It is assumed that the wear in the form of a notch occurs as a result of the machined material becoming glued to the cutting edge, with the subsequent tearing of the tool's base material. The formation of a notch on the cutting edge of the tool thus belongs to the adhesive forms of wear, but can also be related to oxidation wear. The most common causes of notch wear include a change in chip formation, deterioration in the quality of the machined surface and, in some cases, a fracture of the cutting tool.

In order to prevent notch wear during the machining of nickel alloys, it is essential to design a suitable machining strategy, choose the right cutting tool and cutting geometry, and determine suitable cutting conditions. By a suitable combination of these parameters, materials such as nickel alloys can be machined with high process efficiency and tool wear characteristics which is controlled and predictable $[2,7,14]$. 


\section{PROPOSED EXPERIMENTAL ACTIVITY}

The experimental part of the paper aims to verify the effect the angle of the main edge of tool $\kappa_{r}$ has on the formation of notch wear of the tool edge. The Inconel $625 \mathrm{Ni}$ alloy was selected as the machined material. Given its low thermal conductivity and deformation hardening capacity, this alloy meets the requirements for the occurrence of notch wear on the cutting edge of the tool. RCMT 10T3M0 - F2 and SNMG 120412 - MR3 indexable cutting inserts were designed as cutting tools for longitudinal alloy machining, see Fig. 1. In both cases, these are coated cutting inserts with a thin layer of PVD coating (Ti, Al) N + TiN. The type of coating applied and the hard fine-grain structure of the base carbide of the cutting inserts should allow effective machining of materials such as nickel alloys. The geometry of cutting inserts has been designed to ensure maximum relative edge strength, wear resistance, the required stability of the cutting process and the quality of the machined surface.

For the machining of the alloy, the cutting conditions were designed to allow the verification of the effect of the cutting edge angle on the occurrence, course and size of the notch wear. With a constant cutting speed and displacement, two depths of the removed layer of the machined material are proposed, see tab. 1. The entering angle of the cutting insert's edge $\mathrm{k}_{\mathrm{r}}$ changed with the selected cutting depth $a_{p}$. Changes in entering edge angle during machining resulted in changes in the force distribution along the cutting tool edge as well as in the notch wear intensity. The entering angle of edge $\kappa_{r}$ was determined for the selected cutting depth according to formula (1), see table $2[2,3,6,12]$.
The formula for calculating the angle of the main edge $\kappa_{r}$, depending on the selected depth of cut [11].

$$
\cos \kappa_{r}=\frac{\left(0,5 \cdot \mathrm{IC}-\mathrm{a}_{\mathrm{p}}\right)}{0,5 \cdot \mathrm{IC}}\left[{ }^{\circ}\right]
$$

where: $I C$ - insert radius [mm]

ap - depth of cut [mm]

\section{DETERMINING THE EFFECT OF THE MAIN EDGE ANGLE ON THE COURSE OF THE MACHINING OF INCONEL 625}

During the machining of Inconel 625, we assessed the effect of the entering angle and geometry of the cutting tool's on the occurrence and intensity of notch wear. Depending on the selected cutting depth, the angle of the main edge changed during the machining using the proposed cutting inserts. This angle affected the direction and size of the force load, the size of the notch wear, the durability of the cutting inserts and the quality of the machined surface in the machining process.

Table 1. Settings of cutting conditions

\begin{tabular}{|l|l|l|}
\hline Cutting parameters & 1. set & 2. set \\
\hline Cutting speed $-v_{c}\left[\mathrm{~m}_{\mathrm{min}}{ }^{-1}\right]$ & 40 & 40 \\
\hline Feed $-f[\mathrm{~mm}]$ & 0.3 & 0.3 \\
\hline Depth of cut $-a_{o}[\mathrm{~mm}]$ & 0.5 & 1.5 \\
\hline
\end{tabular}

Table 2. The values of entering angle $\mathrm{kr}$

\begin{tabular}{|c|c|c|}
\hline Marking according ISO & $\begin{array}{c}\text { Depth of } \\
\text { cut }-\mathrm{a}_{\mathrm{p}}[\mathrm{mm}]\end{array}$ & $\begin{array}{c}\text { Entering } \\
\left.\text { angle }-\mathrm{k}_{\mathrm{r}}{ }^{\circ}{ }^{\circ}\right]\end{array}$ \\
\hline RCMT 10T3M0 - F2 & 0.5 & 26 \\
\hline RCMT 10T3M0 - F2 & 1.5 & 45 \\
\hline SNMG 120412 - MR3 & 0.5 & 35 \\
\hline SNMG 120412 - MR3 & 1.5 & 45 \\
\hline
\end{tabular}

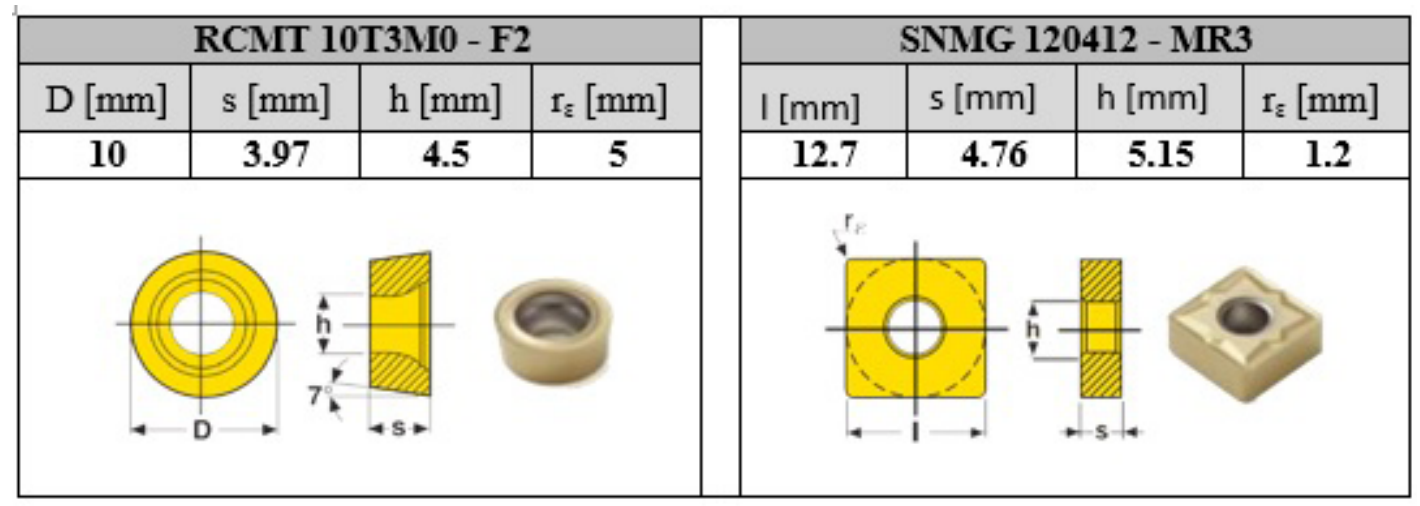

Fig. 1. The geometry of the cutting inserts [13] 
The durability of the cutting insert was selected as the criterion for assessing the effect of the angle of the main edge and the selected geometry of the cutting insert on Inconel 625 machining process. For the determination of durability, selected forms of wear were measured using a direct microscopic method of measurement on the rake and flank of the tool. The intensity of wear was determined by direct measurement of the linear dimensions at the point where the tool was subjected to the most intense wear. In relation to the selected geometry of the cutting inserts, measurements were made of the width of the groove on the rake of the $K B$ tool, the wear on the tip of the $V B_{C}$ tool, the wear of the maximum $V B_{B \max }$ and, primarily, the occurrence of the $V B_{N}$ notch wear was monitored $[1,15]$.

\section{COURSE OF EXPERIMENTAL MACHINING OF ALLOY 625}

The wear measurement of the inserts was in accordance with the international standard ISO 3685. For the machining alloy Inconel 625 was determined the time interval after which the tool was cut under the given cutting conditions. After this $t_{A s}=2 \mathrm{~min}$ interval, the machining process was stopped and the course and amount of wear on the cutting tool was measured. Because during the machining of Inconel 625 by the selected cutting inserts, the wear increase was almost uniform, the value $V B_{B \max }=0.2 \mathrm{~mm}$ was chosen as the critical wear.

With the selected depth of the removed material layer $a_{p}=0.5 \mathrm{~mm}$, the tool SNMG 120412 was used for machining only with the tip radius. The machining conditions were therefore almost comparable to machining with RCMT 10T3M0. This is also evidenced by the wear pattern of the cutting inserts, which was very similar in both cases. A slight difference was seen in the case of the cutting insert SNMG 120412, where higher wear values than those of RCMT 10T3M0 were measured in the first phase, probably due to a lower relative strength of the tip radius. Further measurement showed that the wear pattern of the cutting inserts was gradual without the occurrence of notch wear; therefore, the machining process was terminated prematurely. Due to the small wear of the tool cutting edge, only $V B_{B \max }$ and $V B_{C}$ wear values were measured. In this case, abrasion and the formation of built-up edge on the tool cutting edge contributed to the wear (see Table 3) $[5,8,9]$.

Machining of the Inconel 625 alloy under the given cutting conditions and at cutting depth $a_{p}=1.5 \mathrm{~mm}$ resulted in more wear on tools. In this case, the layer of the machined material was already in contact with the straight part of the cutting edge of SNMG 120412. As a result, the angle of the main cutting edge increased to $\kappa_{r}=45^{\circ}$ for both cutting inserts. Theory says that this is the threshold value for the occurrence of notch wear on the tool cutting edge. For this reason, the cutting edge of the cutting inserts did not show any signs of notch wear when machining Inconel 625 . Even so, the machining of the alloy was stopped prematurely. The reason was the critical value of wear on the rake of the cutting tool. Because the alloy structure consists of very hard abrasive particles and the machined material easily creates a built-up edge (BUE), the wear on the rake face was faster. Therefore, the $V B_{C}, V B_{B}, V B_{B \max } K F$ and $K B$ wear criteria were measured on the tool using the optical method $[1,4,10,16]$.

\section{CONCLUSION}

Refractory and heat-resistant alloys are now widely used and their use in industrial practice is constantly increasing. However, during the machining of these alloys, a number of negative effects occur which affect their machinability. These materials include, for example, nickel-based alloys, whose machinability is more difficult, leading to higher requirements for the machining process. However, the present state of chip machining of nickel alloys is not entirely effective and significantly lags behind the machining of other construction materials.

One of the main reasons for the decreased efficiency of the nickel alloy machining process is the low durability of the cutting tools. Intensive wear (due to, for example, low thermal conductivity of the alloy, deformation reinforcement of the material and its abrasive structure, etc.) leads to the selection of cutting conditions lower by more than half compared to the machining of conventional steel. Therefore, there are ongoing efforts to find a suitable way to prevent this wear and to achieve a higher durability of cutting tools.

Inconel 625, which is among HRSA nickelbased alloys, was proposed as the machining material. During machining, the wear of the tool 
Table 3. Course of cutting edge at a cutting depth ap $=0.5 \mathrm{~mm}$

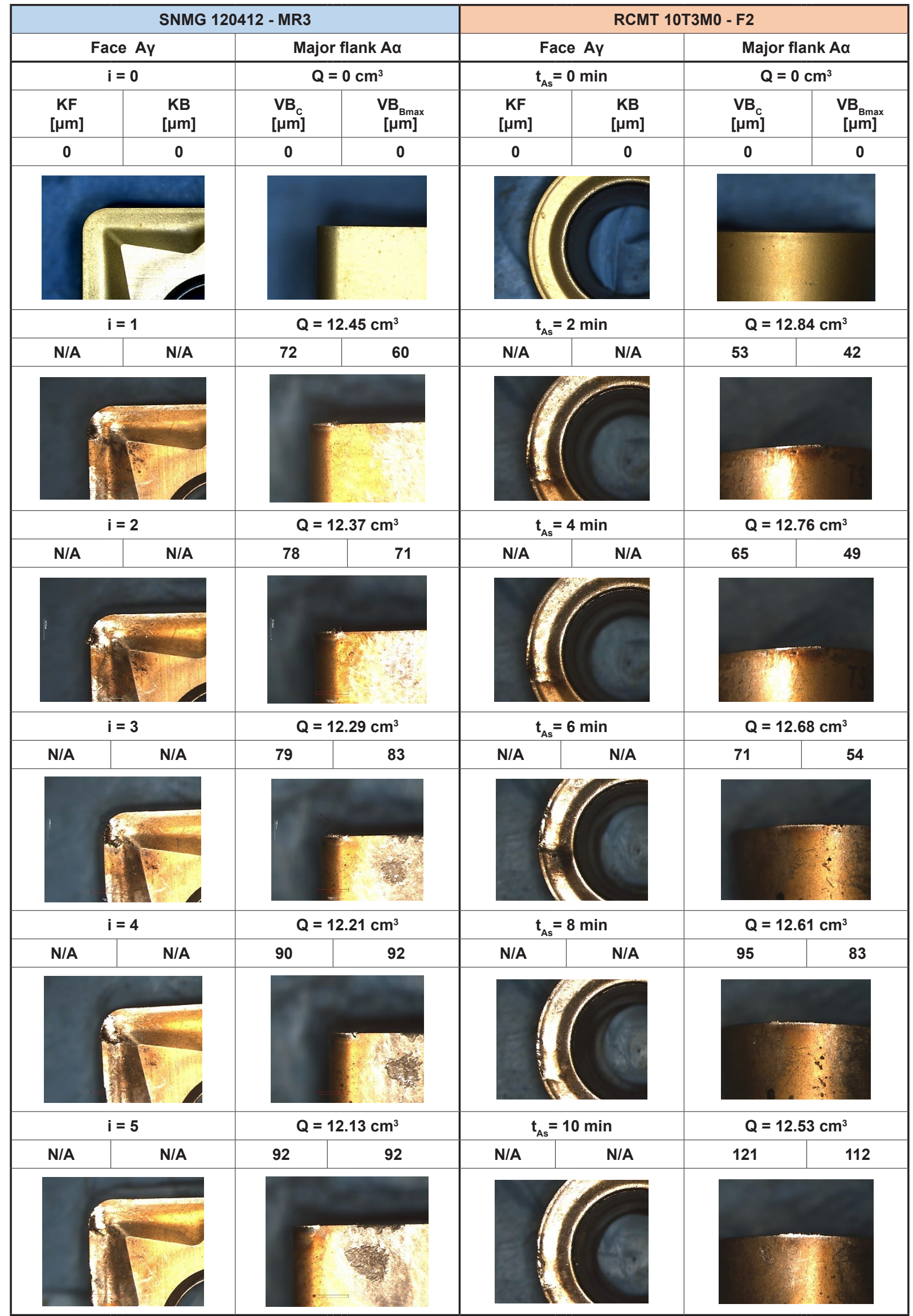




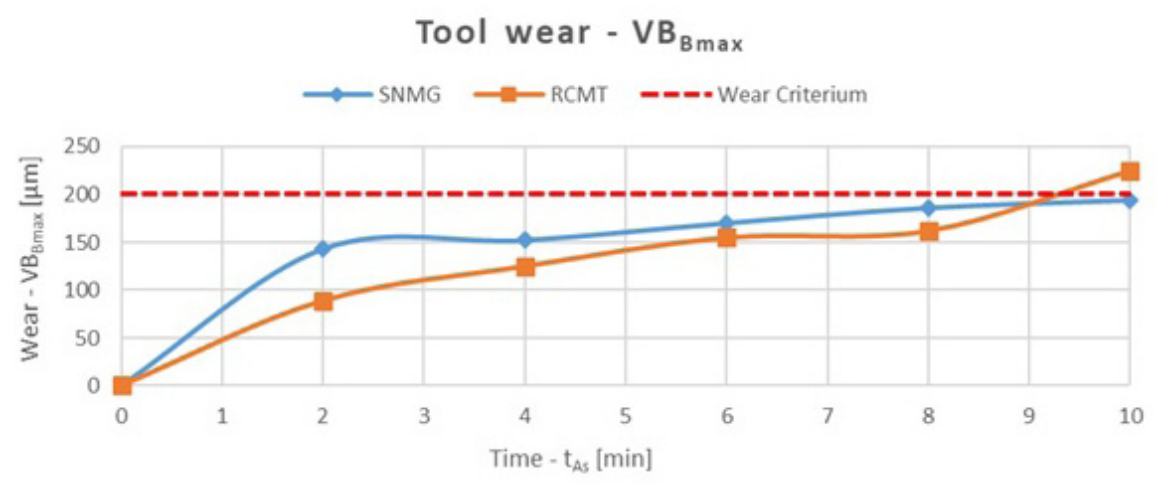

Fig. 2. Dependence of wear VBBmax on time at cut depth ap $=0.5 \mathrm{~mm}$

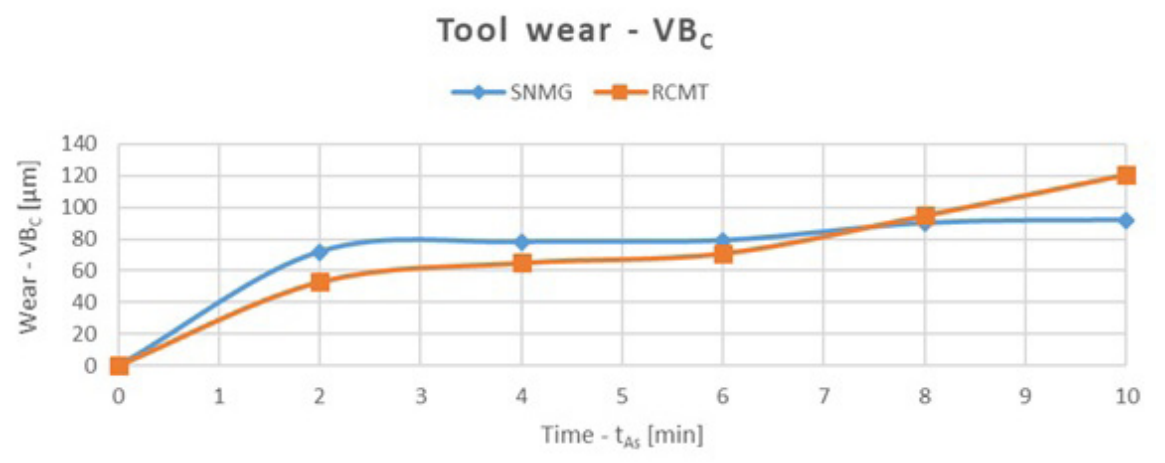

Fig. 3. Dependence of wear VBc on time at cut depth ap $=0.5 \mathrm{~mm}$

cutting edge in the shape of a notch is typical. This form of wear occurs on both the flank and the rake of the tool due to high temperature and mechanical stress at the cutting point. Intense mechanical stress is due to the interaction between the tool cutting edge and the reinforced layer of the machined material. This reinforced layer has completely different mechanical properties and, in particular, higher strength than the base material. Thus, notch wear occurs most often at the point where the tool comes out of engagement, i.e. at a distance between the maximum depth of cut and the tool tip.

For the machining of Inconel 625, cutting tools have been designed, the geometry of which makes it possible (in combination with cutting conditions) to prevent notch wear. The angle of the main tool cutting edge $\mathrm{k}_{\mathrm{r}}$ has a substantial effect on the occurrence of notch wear. The angle $\kappa_{r}=45^{\circ}$ is more favourable for the distribution of force relationships during machining. The mechanical load is therefore not oriented only in one direction, but is evenly distributed in three directions. This was also proved by the wear pattern of the cutting inserts during machining of
Inconel 625. For the selected geometries of the cutting inserts and the proposed cutting conditions with a cutting depth $a_{p}=0.5$ and $1.5 \mathrm{~mm}$, the angle of the main cutting edge was $\kappa_{r}<45^{\circ}$. Under these conditions, the cutting edges of cutting inserts did not show any signs of notch wear. In spite of this relative resistance of the cutting inserts to notch wear, the tool's rake and flank were subject to very intensive wear. This wear was due to very hard particles contained in the structure of the material, which caused abrasive wear (abrasion on the flank and groove on the rake of the tool). In the case of machining with a $1.5 \mathrm{~mm}$ cutting depth, the wear on the rake was so intense that the Inconel 625 machining process had to be prematurely terminated without the selected wear criterion being reached on the cutting inserts. In addition to the abrasive wear mechanism, the occurrence of built-up edge (BUE) and its unstable part also contributed to the strong cutting edge damage. The adhesion of the machined material to the surface of the cutting tool and its subsequent tearing caused the emergence of craters on the tool cutting edge reducing its strength. 
Table 4. Course of cutting edge at a cutting depth ap $=1.5 \mathrm{~mm}$

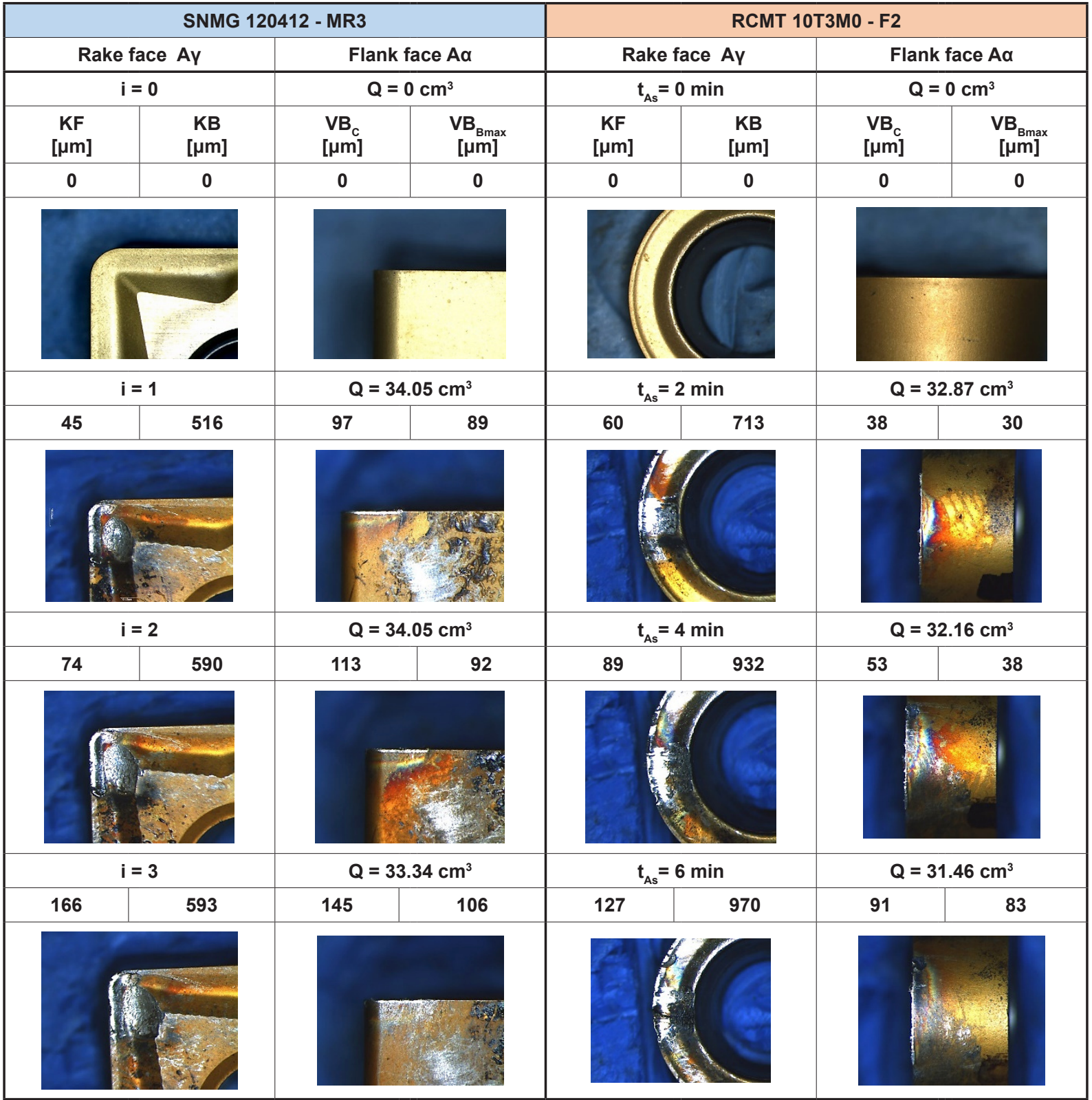

Tool wear - VB $B_{B \max }$

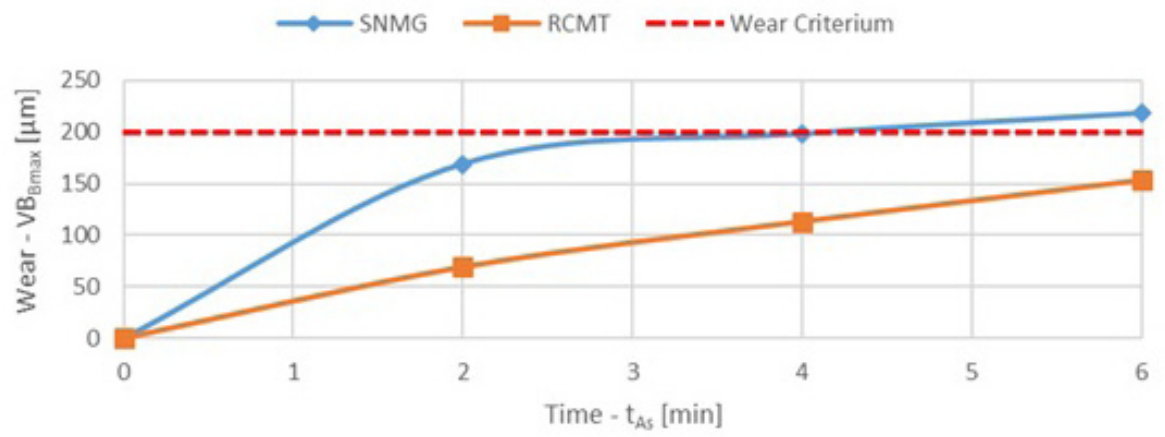

Fig. 4. Dependence of wear VBBmax on time at cut depth ap $=1.5 \mathrm{~mm}$ 


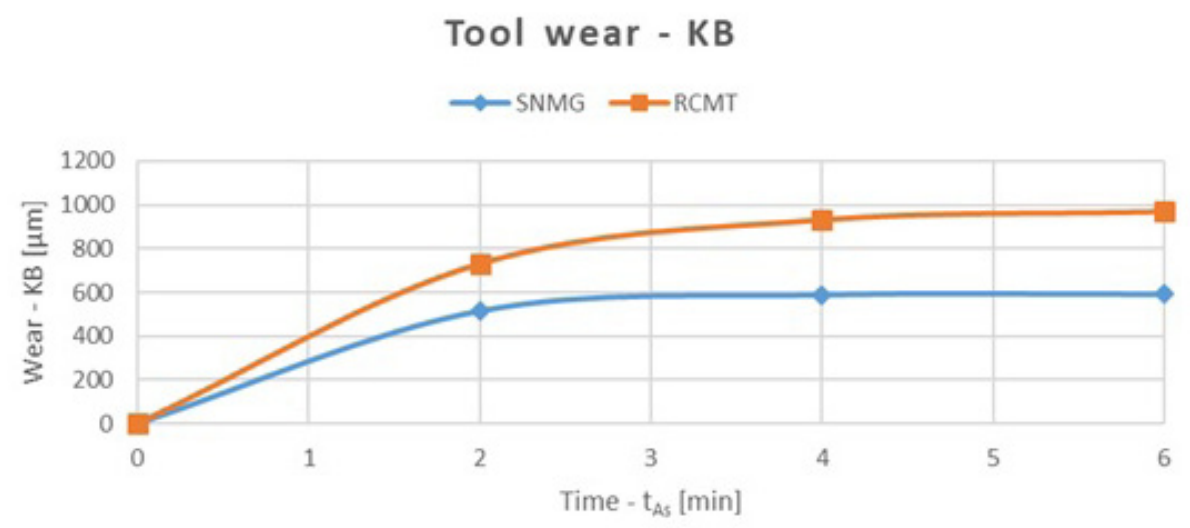

Fig. 5. Dependence of wear KB on time at cut depth ap $=1.5 \mathrm{~mm}$

The graphical comparison of the wear of both selected geometries of the cutting inserts shows that the RCMT 10T3M0 - F2 geometry had a higher flank wear resistance than the SNMG 120412 - MR3 during Inconel 625 machining. This could be due to the fact that the circular geometry of the cutting insert is better able to withstand stress along the entire part of the cutting edge, which is leaning towards the cut with the machined material. For machining with a cutting depth of $1.5 \mathrm{~mm}$, the cutting inserts were in contact with a larger diameter of the removed layer of material. The outgoing chips and hard carbides caused more intensive wear on the rake of RCMT 10T3M0 - F2 than in the case of SNMG 120412 - MR3. The wear of the rake of a tool with circular geometry and the occurrence of built-up edge proved to be the main cause for the termination of the tests preceding the breakage of the tool cutting edge.

The wear of cutting tools is currently a very common thing, which cannot be avoided during machining. The only thing we can do is find a way to reduce tool wear, make it predictable and fully controllable in the machining process. By changing the tool geometry and selecting the right cutting conditions, some improvements can be achieved, but in many cases finding the right combination to prevent wear is rather a matter of compromise.

\section{Acknowledgement}

Article has been done in connection with projects Education system for personal resource of development and research in field of modern trend of surface engineering - surface integrity, reg. no. CZ.1.07/2.3.00/20.0037 financed by Structural
Founds of Europe Union and from the means of state budget of the Czech Republic and by project Students Grant Competition SP2017/147 and SP2017/149 financed by the Ministry of Education, Youth and Sports and Faculty of Mechanical Engineering VŠB-TUO.

\section{REFERENCES}

1. Astakhov V. P., Davim J. P. Tools (Geometry and Material) and Tool Wear. Machining Fundamentals and Recent Advances, 2008, Hardcover.

2. Bakša, T., Morávek, M., Zetek, M. Influence of the coated carbide grade on the cutting tool life when machining inconel 718. Engineering Materials and Tribology, 674(24), 2016, 271-276.

3. Ezugwu, E.O., Wang, Z.M., Machado, A.R. The machinability of nickel-based alloys: A review. Journal of Materials Processing Technology, 86(1-3), 1998, 1-16.

4. Hao, Z.P., Fan, Y.H., Lin, J.Q., Yu, Z.X. Wear characteristics and wear control method of PVD-coated carbide tool in turning Inconel 718. International Journal of Advanced Manufacturing Technology, 78(5-8), 2015, 1329-1336.

5. ISO 3685:1993 (1993). Tool-life testing with single-point turning tools. Geneva, International Organization for Standardization, pp. 48.

6. Lotfi, M., Ashrafi, H., Amini, S., Akhavan Farid, A., Jahanbakhsh, M. Characterization of various coatings on wear suppression in turning of Inconel 625: A three-dimensional numerical simulation. Proceedings of the Institution of Mechanical Engineers, Part J: Journal of Engineering Tribology, 231(6), 2017, 734-744.

7. Neslušan, M., Czán, A. 2001. Obrábanie titánových a niklových zliatin. Žilina: EDIS.

8. Petru, J., Zlamal, T., Mrkvica, I, Cep, R. The effect 
of thermal shocks on wear of exchangeable sintered carbide inserts during the cutting proces. Manufacturing Technology, 14(4), 2014, 590-596.

9. Pokusová, M., Brúsilová, A., Šooš, L., Berta, I. Abrasion wear behavior of high-chromium cast iron. Archives of Foundry Engineering, 16(2), 2016, 69-74.

10. Prokes, T., Mouralova, K., Kovar, J. Experimental evaluation on the quality of machined surface after turning of material inconel 625. MM Science Journal, 2016, 1617-1620.

11. SANDVIK Coromant. Př́ručka obrábění. Praha : Scientia, s.r.o. Praha, 1997, pp. 910.

12. Schorník, V., Zetek, M., Daňa, M. The influence of working environment and cutting conditions on milling nickel - based super alloys with carbide tools. Energy Procedia, 100(C), 2015, 1262-1269.
13. Seco Tools Cz, s.r.o. Soustružení [online]. [cit. 2016-05-13]. Dostupné z: http://www.secotools. com/CorpWeb/Downloads/seconews2_2011/MN/ turning/Turning\%202012_CZ_LR.pdf

14. Shankar, V., Bhanu Sankara Rao, K., Mannan, S.L. Microstructure and mechanical properties of Inconel 625 superalloy. Journal of Nuclear Materials, 288 (2-3), 2001, 222-232.

15. Stančeková, D., Šteklač, D., Petrů, J., Zlámal, T., Sadílek, M., Janota, M.; Kordík, M. Influence of machining and heat treatment on deformations of thin-walled bearings. Materials Science Forum, 862, 2016, 49-58.

16. Thakur, D.G., Ramamoorthy, B., Vijayaraghavan, L. Study on the machinability charateristics of superalloy Inconel 718 during high speed turning. Materials and Design, 30(5), 2009, 1718-1725. 